\title{
Otizm Spektrum Bozukluğu ve Down Sendromlu Çocukların Bakım Verme Yüklerinin Zarit Bakım Verme Yüikü Ölçeği ile Değerlendirilmesi
}

\author{
Evaluation of Caregiving Load From Caring For Children With Autism And Down \\ Syndrome Through Zarit Burden Interview
}

\section{Turgay Çokyaman ${ }^{1}$, Fatih Battal ${ }^{2}$}

${ }^{1}$ Çanakkale Onsekiz Mart Üniversitesi Tip Fakültesi Çocuk Sağlığı ve Hastalıkları Anabilim Dalı; Çocuk Nörolojisi, Çanakkale, Türkiye

${ }^{2}$ Çanakkale Onsekiz Mart Üniversitesi Tip Fakültesi Çocuk Sağlığı ve Hastalıkları Anabilim Dalı Çanakkale, Türkiye

Yazı̧̧ma Adresi / Correspondence:

Fatih Battal

Canakkale Onsekiz Mart Üniversitesi Tip Fakültesi Araștırma Hastanesi

Barbaros Mahallesi Prof. Dr. Sevim BULUÇ Sokak Terzioğlu Yerleşkesi A Blok No:2 B Blok No:4 Çanakkale

T: +902862635950 E-mail : battalfatih@hotmail.com

Geliş Tarihi / Received : 14.02.2019 Kabul Tarihi / Accepted : 01.05.2020

Orcid :

Turgay Çokyaman https://orcid.org/ 0000-0002-7108-6839

Fatih Battal https://orcid.org/ 0000-0001-9040-7880

( Sakarya Tip Dergisi / Sakarya Med J 2020, 10(2):210-215) DOI: 10.31832/smj.527308

\footnotetext{
Öz

Amaç Otizm Spektrum Bozukluğu (OSB) ve Down Sendromlu (DS) çocuklarda hafiften ağıra kadar değișebilen düzeylerde zihinsel yetersizlik görülmektedir. Zihinsel yetersizliği olan bu çocukların kişisel bakım, gelişim ve sosyal yaşantıları birtakım destekler gerektirmektedir. Gerekli bakım ve destekleri veren bu bireylere birtakım yükler binmektedir. Bu çalışmada OSB ve DS çocuklara bakım verenlerin bakım yüklerinin karşılaştırılması amaçlanmıștır.

Gereç ve Kesitsel ve prospektif olarak tasarlanan bu çalışmaya 01 Ocak 2018 ile 01 Ocak 2019 tarihleri arasında Çanakkale Onsekiz Mart Üniversitesi Hastanesỉnin Çocuk Sağlığı ve Yöntem Hastalıkları Anabilim Dalına bağlı acil servis, poliklinikler ve servisinde ayaktan veya yatırılarak takip veya tedavi edilen OSB veya DS'li cocukların bakım verenleri dahil edildi. 18 yaşından büyük ve en az 1 yıldır bakım verenler gönüllülük esası ile çalışmaya alınmıștır. Bakım verenlerin yaş, cinsiyet, eğitim durumu, medeni hal, meslek, maddi gelir düzeyi gibi sosyodemografik özellikleri ve Zarit Bakım Verme Yükü Ölçeği (ZBYÖ) ile bakım verme yükleri belirlendi.

Bulgular Çalş̧maya toplam 91 (46 OSB, 45 DS) bakım veren katıldı. Bakım verenlerin çoğunluğu (\%91) kadındı. OSB grubunda bakım verenlerin yaş ortalaması 37,73 yll $\pm 7,82$ ve DS grubunda ortalama 43,24 yl $\pm 10,71$ idi (p:0,008). ZBYÖ toplam puan ortalaması OSB grubunda 51,81 $\pm 15,84$ iken DS grubunda $42,42 \pm 13,52$ puan bulundu ve bu fark anlamlı idi (p:0,003)

Sonuç Calıșmamızda DS’ye bakım veren kișilere göre OSB tanılı çocuklara bakım verenlerin bakım yükünün daha yüksek olduğunu saptadık. Araștırmamızın OSB’li çocuklara bakım verenlerin yaşadıkları güçlükleri tanımada ileride yapılacak daha kapsamlı çalışmalara referans olacağını düşünmekteyiz.

Anahtar bakım veren; bakım verme yükü, otizm spektrum bozukluğu; down sendromu

Kelimeler

Abstract

Objective Children with autism spectrum disorder (ASD) and Down syndrome (DS) often experience mild to severe mental problems. Mental inadequacy of these children requires some support in terms of personal care, development and social life. This situation may cause a considerable burden on caregivers of those children. Therefore, needs of the caregivers are also important. The aim of this study was to compare caregiving burdens of the caregivers of children with ASD and DS.

Materials Caregivers older than 18 years of age responsible for the care of children with ASD and DS were included in this cross-sectional and prospective study on a voluntary basis between 1th January and methods 2018 and 1th January 2019 attending to Canakkale Onsekiz Mart University Hospital emergency room, outpatient clinic and clinic of pediatrics department. Caregivers sociodemogrpahic characteristics like age, sex, education and marital status, jobs and financial income and caregiving loads were evaluated through the Zarit Caregiver Burden Scale (ZCBS).

Results A total of 91 (46 ASD, 45 DS) caregivers participated in the study. The majority (91\%) of caregivers were female. The mean age of caregivers was $37.73 \pm 7.82$ years in the ASD group, 43.24 \pm 10.71 years in the DS group ( $p: 0.008$ ). While the mean total score of ZCBS was $51.81 \pm 15.84$ points in the ASD group, it was $42.42 \pm 13.52$ points in the DS group ( $p: 0.003$ ). Conclusion: In our study, we found that the burden of care for ASD is more than burden of car efor DS. The present study may be a reference for more comprehensive studies about the burden of care for caregivers of autism.

Conclusion In our study, we found that the burden of care for ASD is more than burden of car efor DS. The present study may be a reference for more comprehensive studies about the burden of care for caregivers of autism.

Keywords caregivers; caregiver burden; autism spectrum disease; down syndrome.
} 


\section{GIIRIș}

Otizm Spektrum Bozukluğu (OSB); çeşitli düzeylerde zihinsel ve entelektüel yetersizlik, zayıf veya yetersiz göz teması gibi bulgular ile karakterize durumu tarif etmek için kullanılan bir terim olup bu çocuklarda da hafiften ağır düzeye kadar değiş̧ebilen zihinsel yetersizlik görülebilir. ${ }^{1}$ OSB tanılı çocuğun kişisel bakımını sağlayabilmek, özel gereksinimlerini karşılamak, çeşitli görevleri başarmasında yardımcı olmak, okul hayatının aksamamasını sağlamak, sosyal becerilerini geliştirmek gibi sorumluluklar bakım verende stres oluşturabilir ve çoğunlukla bakım veren pozisyonunda olan anne ya da baba bunları gerçekleştirmeye çalışırken kendi yaşamlarını ve sağlıklarını ihmal edebilir. ${ }^{2}$ Genellikle bakım verici pozisyonunda olan ebeveynler çocuğun bu yetiştirilme sürecini ağır bir yük olarak görerek çocuklarına destek olmada yetersiz hissetiklerini düşünüp depresyon ve anksiyete bozukluğuyla karşılaşabilirler. ${ }^{3}$

Down Sendromu (DS) 21. Kromozom trizomisinden kaynaklanan konjenital kalp anomalileri, hipotiroidi, çekik göz ve simian çizgilerinin eşlik ettiği medikal durumlarla birlikte bilişsel fonksiyonların da etkilendiği özel bulgulara sahip bir durumdur. ${ }^{4}$ DS'de hafiften ağır düzeye kadar değişebilen zihinsel yetersizlik görülmekle birlikte çoğunlukla orta düzeyde zihinsel yetersizlik eşlik eder. ${ }^{5}$ Konjenital kalp defekti gibi kronik hastalıkların varlı̆̆ı, hipotiroidizm ve immünolojik bozukluklar DS'li çocukların bakıcılarının yaşamının birçok yönünü etkileyerek yorgunluk ve strese yol açabilir. ${ }^{6}$ ilaveten DS'li çocuğun bakımından sorumlu olanlar kendilerini yetersiz hissedebilir. $^{7}$

OSB ve DS de akademik öğrenme becerileri, konsantrasyon becerileri, kendini kontrol etme, kendine güven, soyut düşünce, hemisferik özelleşme gibi yeteneklerin gelişimi gecikebilir. ${ }^{1,4}$ İşlevsellikte gecikmenin eşlik etmesi OSB ve DS’nin ortak bulguları olsa da sosyal etkileşimden yoksun kalma davranışsal ve dil bozukluklarının daha yoğun eşlik ettiği $\mathrm{OSB}^{1}$; konjenital kalp hastalığı, immun yetmezlik, hipotiroidi gibi hastalıkların eşlik ettiği DS'den ${ }^{5}$ ayrışır. Bu durum bakım verende farklı bir strese ve zorluğa neden olabilir. Literatürde bu hastalığa bakım verenleri karşılaştıran araştırmalar kısıtlı olup Siklos ve ark. yaptığ 1 bir çalışmada OSB ve DS sahip ebeveynlerin sosyal destek yönü araştırılmıştır. ${ }^{8}$ Biz literatürden farklı olarak çalışmamızda OSB ve DS gibi bakım vermeyi gerektiren hastalığa sahip çocuklara bakım veren bireylerin bakım yüklerini karşılaştırmayı amaçladık.

\section{GEREÇ ve YÖNTEMLER}

Kesitsel tipte tanımlanan bu araştırmaya Etik Kurul Başkanlığından 14.11.2017 tarih 2011-KAEK27/201-E.1800147967 sayılı onay alındıktan sonra Ocak 2018 ile Ocak 2019 tarihleri arasında Çanakkale Onsekiz Mart Üniversitesi Hastanesi’nin Çocuk Sağlığı ve Hastalıkları Anabilim Dalına bağlı acil servis, poliklinikler ve servisinde ayaktan veya yatırlarak takip veya tedavi edilen OSB veya DS çocukların bakımlarından en az 1 yıldır sorumlu ve 18 yaşından büyük bakım verenler dahil edildi. Bakım hizmeti karşılında devletin verdiği yardım dışında herhangi bir ücret alanlar ve bu işi meslek olarak yapan aile bireyleri dışındaki kişiler ise çalışmaya dahil edilmedi. Bakım verenlerin yaş, cinsiyet, eğitim durumu, medeni hal, meslek, maddi gelir, bakım verdiği alanlar ve hastaların tanıları standart veri giriş formuna kaydedildi. $\mathrm{Bu}$ tanıtıcı soru formu ile birlikte Zarit Bakım Verme Yükü Ölçeği çalışmaya katılanlara verildi ve aynı gün içerisinde formlar geri toplandı. Anketler onam formları alındıktan sonra uygulandı. Değerlendirme bakım verenler ile yüz yüze görüşme tekniği ile yapıldı. Her bir katılımcı için 1015 dakika sürdü.

\section{Zarit Bakım Verme Yükü Ölçeği}

Ruhsal ve fiziksel sağllğa, sosyal ve duygusal yaşantılara, ekonomik duruma, kişiler arası ilişkilere yönelik 19 sorudan oluşan Zarit ve arkadaşları tarafından geliştirilmiş bakım gereksinimi olan bireye bakım verenlerin yaşadığı stresi değerlendirmek amacıyla kullanılan Zarit Bakım Verme Yükü Ölçeği (ZBYÖ), bakım verenleri değer- 
lendirmek için kullanıldı. ${ }^{9}$ Ölçek puanının yüksek olması yaşanılan yükün fazla olduğunu göstermektedir. Bakım verenin verebileceği en düşük puan 19, en yüksek puan 95'dir. Ölçek 'asla', 'nadiren', 'bazen', 'sık sık' ya da 'hemen her zaman' şeklinde 1'den 5'e kadar değişen likert tipi değerlendirmeye sahiptir. 2008 de İnci ve arkadaşları tarafından Türkçeye uyarlanarak geçerlilik ve güvenilirlik çalışması yapılmıştır. ${ }^{10}$

\section{İstatistiksel Analiz}

İstatistiksel verilerin değerlendirilmesinde bilgisayar ortamında IBM Statistics 20.0 (SPSS) istatistik paket programı kullanıldı. Tanımlayıcı verilerin sunumunda sayı, yüzde, ortalama, standart sapma kullanıldı. Demografik özelliklerin karşılaştırılmasında ikili kategorik değişkenler için Ki-kare testi veya Fisher testi (Ki-kare testi varsayımları sağlanamadığı durumlarda) kullanıldı. Sayısal değişkenler karşılaştırılmasında İndependent-samples $\mathrm{t}$ testi kullanıldı. Tüm istatistik analizlerde anlamlılık düzeyi p $<0,05$ olarak kabul edildi.

\section{BULGULAR}

Çalışmaya toplam 91 (46 OSB, 45 DS) bakım veren katıldı. Bakım verenlerin \%91'i kadındı. Bakım verenlerin yaşları OSB grubunda ortalama 37,73 yil $\pm 7,82$ ve DS grubunda ise daha büyük olup ortalama 43,24 $\pm 10,71$ yıl idi (p:0,008). Bakım verenlerin \%47'si ilkokul, \%31'i lise, \%15'i üniversite mezunu idi ve \%7'si ise hiç eğitim almamıştı. Eğitim düzeyi ilkokul ve altı, lise ve üzeri eğitim şeklinde kategorize edildiğinde OSB ve DS bakım verenleri arasında farklılık saptanmadı. Bakım verenlerin toplam \%82'si evli, \%11'i boşanmış ve \%5'i bekar idi. Medeni durum evli ve evli olmayanlar şeklinde gruplandırıldığında OSB ve DS bakım verenleri arasında anlamlı farklılık saptanmadı. Tüm bakım verenlerin sadece \%14’ü çalışıyordu. OSB ve DS bakım verenleri arasında çalışma oranları farklı bulunmadı (p:0,392). Bakım verenlerin \%55'inin gelir düzeyi 2000 TL ve altı, \%45’inin 2000 TL üstünde idi. Ancak OSB ve DS bakım verenleri arasında gelir düzeyi farklılığı saptanmadı. Bakım verme yükünü üstlenen bireylerin çoğunluğunu anneler (\%88), diğer bireylerin \%12 olduğu görüldü ve gruplar arasında farklılık yoktu (Tablo 1).

\begin{tabular}{|c|c|c|c|c|}
\hline & & $\begin{array}{c}\text { Otizm } \\
\text { Spektrum } \\
\text { Bozukluğu }\end{array}$ & $\begin{array}{c}\text { Down } \\
\text { Sendromu }\end{array}$ & p değeri \\
\hline \multicolumn{2}{|l|}{$\begin{array}{l}\text { Yaş } \\
(\text { Ort } \pm S D)\end{array}$} & $37,73 \pm 7,82$ & $43,24 \pm 10,71$ & $0,008^{*}$ \\
\hline & & n (46) & n (45) & \\
\hline \multirow{2}{*}{ Cinsiyet } & Kadın & 41 & 42 & $0,714^{* *}$ \\
\hline & Erkek & 5 & 3 & \\
\hline \multirow{2}{*}{$\begin{array}{l}\text { Eğitim } \\
\text { düzeyi }\end{array}$} & İlkokul ve altı & 24 & 25 & $0,746^{a}$ \\
\hline & Lise ve üzeri & 22 & 20 & \\
\hline \multirow{2}{*}{$\begin{array}{l}\text { Medeni } \\
\text { durum }\end{array}$} & Evli & 37 & 38 & $0,615^{\mathrm{a}}$ \\
\hline & Evli olmayan & 9 & 7 & \\
\hline \multirow{2}{*}{$\begin{array}{l}\text { Çalıșma } \\
\text { durumu }\end{array}$} & Çalışıyor & 8 & 5 & $0,392^{\mathrm{a}}$ \\
\hline & Çalışmiyor & 38 & 40 & \\
\hline \multirow{2}{*}{$\begin{array}{l}\text { Gelir } \\
\text { düzeyi }\end{array}$} & $\leq 2000 \mathrm{TL}$ & 26 & 24 & $0,760^{\text {a }}$ \\
\hline & $>2000 \mathrm{TL}$ & 20 & 21 & \\
\hline \multirow{2}{*}{$\begin{array}{l}\text { Bakım } \\
\text { verenin } \\
\text { yakınlığı }\end{array}$} & Anne & 40 & 40 & $0,777^{\mathrm{a}}$ \\
\hline & Diğer & 6 & 5 & \\
\hline
\end{tabular}

ZBYÖ toplam puan ortalamaları OSB grubunda $51,81 \pm 15,84$ puan, DS grubunda $42,42 \pm 13,52$ puan idi (p:0,003) Eğitim ve gelir düzeylerine göre bakım verenlerin OSB ve DS ZBYÖ puanları karşılaştırıldı̆̆ında anlamlı farklılık saptanmadı (p:0,857; p:0,409) (Tablo 2).

Tablo 2. Zarit Bakım Verme Yüküi Ölçeği Puanlarının Karşılaştırılması

\begin{tabular}{|l|c|c|c|}
\hline & $\begin{array}{c}\text { Otizm } \\
\text { Spektrum } \\
\text { Bozukluğu }\end{array}$ & $\begin{array}{c}\text { Down } \\
\text { Sendromu }\end{array}$ & $\begin{array}{c}\text { p } \\
\text { değeri* }^{*}\end{array}$ \\
\hline $\begin{array}{l}\text { Bakım verenlerin } \\
\text { puan ortalamaları }\end{array}$ & $51,81 \pm 15,84$ & $42,42 \pm 13,52$ & 0,003 \\
\hline \multirow{2}{*}{$\begin{array}{l}\text { Eğitim düzeyine göre } \\
\text { bakım verenlerin } \\
\text { puan ortalamaları }\end{array}$} & İlkokul ve altı & Lise ve üstü & \multirow{2}{*}{0,857} \\
\cline { 2 - 3 } & $47,42 \pm 16,34$ & $46,83 \pm 14,41$ & \\
\hline $\begin{array}{l}\text { Gelir düzeyine göre } \\
\text { bakım verenlerin } \\
\text { puan ortalamaları }\end{array}$ & $\leq \mathbf{2 0 0 0} \mathbf{T L}$ & $>\mathbf{2 0 0 0}$ tl & \multirow{2}{*}{0,409} \\
\cline { 2 - 3 } & $45,91 \pm 15,13$ & $48,62 \pm 15,82$ & \\
\hline * Independent-samples $\mathrm{t} \mathrm{test}$ & & \\
\hline
\end{tabular}




\section{TARTIŞMA}

OSB ve DS sosyal etkileşimde eksiklik, işlevsellikte ömür boyu gecikme ile bazı davranışsal ve dil bozukluklarının eşlik ettiği durumlardır. OSB ve DS gibi bakım vermeyi gerektiren hastalıkların bakım yüklerini karşılaştırdığımız bu çalışmada OSB'li çocuklara bakım verenlerin daha yüksek skorda bakım yükünü tespit ettik.

Tel ve ark. Kronik Obstrüktif Akciğer Hastalığı olan erişkinlerde yaptıkları araştırmada hastaların yaşlarına göre bakım verenin yükü incelendiğinde istatistiksel olarak anlamlı farklılık saptanmamakla birlikte hasta yaşı arttıkça bakım verenin yükünün arttığını bildirmişlerdir. ${ }^{11}$ Bazı çalışmalarda bakım yükünün yaşa göre farklılık göstermediği bildirilmişken, bazı çalışmalarda ise özellikle genç yaş grubunda olan bakım verenlerin daha fazla yük altında oldukları bildirilmiştir. ${ }^{12,13}$ Türe ve arkadaşlarının yaptığı çalışmada ise bakım yükü ile bakım verenlerin yaş grupları incelendiğinde, 40 yaş üzerinde olan ağır derecede yüke sahip olduğunu duyurmuşlardır. Bu durum ileri yaşta bakım verenlerin gençlere kıyasla özellikle fiziksel performans açısından daha çok zorlanıyor olabileceği şeklinde yorumlanmıştır. ${ }^{14}$

Bizim araştırmamızda ise bakım verenlerin yaşları OSB grubunda ortalama 37,73 yll $\pm 7,82$ ve DS grubunda ise daha büyük olup ortalama 43,24 $\pm 10,71$ yl idi (Tablo 1). Artmış maternal yaş ile DS'li bir fetusa sahip olma riski de artış gösterir. ${ }^{15}$ Çalışmamızda bakım verenlerin çoğunu anneler oluşmaktadır (Tablo 1). İleri yaşta anne olmanın DS’li bebeğe sahip olma riskini arttırdığ için yaş ortalamasının daha yüksek bulduğumuzu düşünmekteyiz. Literatür incelendiğinde, bakım verenlerin çoğunlukla kadınlardan oluştuğu görülmekle birlikte çoğu kültürde de bakım verme görevi sadece kadınlarınmış gibi algılanmaktadır. ${ }^{16}$ Bizim araştırmamızda literatürle uyumlu olarak bakım verenlerin çoğunu kadınlar oluşturmaktadır (Tablo 1). Çocukluk yaş grubunda anneye karşı olan sevgi bağı ve kadının sahiplenici, koruyucu özellikleri dikkate alındığında, toplumumuzda araştırmamızdaki gibi rahatsızlığı olan çocuklu ailelerde çocuğun bakımında annelerin daha fazla sorumluluk üstlendiğini düşündürmektedir.

Kronik hastalıklar hastayı ve bakım verenleri maddi, sosyal, duygusal, davranışsal ve bilişsel açıdan çeşitli zorlukların içerisine sokabilir. Hastaneye yapılan ziyaretler, tedavi ve ilaç masrafları yanında ebeveynlerden birinin çocuğun bakımını üstlenmek için işinden ayrılmak zorunda kalması da ailede gelir kaybına neden olabilir. ${ }^{17}$ Alahan ve arkadaşlarının kronik hastalığa sahip ebeveynlerin bakım verme yükünü inceledikleri çalışmada, ekonomik durumu kötü olan ailelerin bakım verme yükü puanlarının daha yüksek olduğu tespit edilmiştir. ${ }^{18}$ Bizim

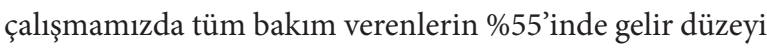
2000 TL'nin altında idi.

Zihinsel yetersizliği olan çocuğa sahip ailelerle ilgili yapılmış çalışmalarda stres, keder, kaygı, evlilik memnuniyeti gibi aile yükünün duygusal boyutu incelenmiştir. ${ }^{19}$ Bakım verenlerin içinde bulunduğu kısıtlılık ve yük aile ve sosyal ilişkilerinde yıpranmaya hatta ekonomik güçlüklere neden olabilir. ${ }^{20}$ Literatürde çocuk acil kliniğine başvuran mental-motor retardasyon, epilepsi, hipoksik iskemik ensefalopati, nörometabolik hastalık, hidrosefali, spinal müsküler atrofi, duchenne müsküler distrofi, kronik böbrek yetmezliği, karaciğer yetmezliği, kistik fibrozis ve lösemi gibi kronik hastalık nedeni ile takip edilen hastaların bakım verenlerinin yükünü araştıran Türe ve ark. çalışmalarında ZBYÖ puan orta-

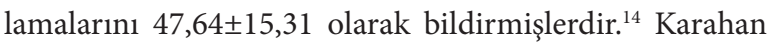
ve arkadaşlarının yaptığı başka bir çalışmada ise serebral palsili çocukların bakım verenlerinde bakım yükü ölçeği puan ortalaması $40.70 \pm 6.87$ olarak bulunmuştur. ${ }^{21}$ Bizim çalışmamızda ZBYÖ toplam puan ortalamaları OSB grubunda $51,81 \pm 15,84$ puan iken DS grubunda $42,42 \pm 13,52$ puan idi. Araştırmamızda özellikle OSB çocukların bakım yükü puan ortalamasında yükseklik dikkati çekmektedir (Tablo 2). Otistik çocukların kişilerarası iletişimde sorun yaşaması, sosyal ilişkileri ve sosyal gelişimi diğer çocuklardan farklılık arz etmesi ve bu çocukların faaliyetlerinin 
kısıtlı ve yineleyici olmasından dolayı bakım verenlerin fazla enerji harcayabileceğini ifade eden çalışmalar vardır. ${ }^{2,22}$ Otistik çocuğa sahip olan aileler çocuklarının tedavi aşamalarında birçok zorluk yaşarlar. Otistik çocuğun aileye bağımlı olması ve ailenin gelecekte bu çocuğa ne olacak kaygısı, bakımlarını kimlerin yapacağı ve nasıl bir yaşam sürdüreceği konusunda endişeleri bakım verenin daha fazla zaman harcamasına neden olabilir. ${ }^{22,23,24} \mathrm{Ek}$ olarak otistik çocukların davranışlarını düzeltmesi, değiştirmesi ve geliştirmesinde bakım verenin üstlendiği rolden ya da bakım verenin otistik çocuğun uygunsuz davranışları karşısında çevrenin onlara karşı anlayışlı olmayacakları algısı bu yükü arttırabilir. ${ }^{2,24}$ Araştırmamızda OSB grubunda bu nedenlerle OSB'li çocuklara bakım verenlerin ZBYÖ puan ortalamaları yüksek çıkmış olabilir. Fiziksel, psikolojik, duygusal, sosyal zorluk çeken bakım verenlerin ekonomik durumunun da kötü olması hastasının temel ihtiyaçlarını dahi karşılamada zorluklara neden olabilir. Datta ve ark. araştırmalarında bakım verenlerin eğitim düzeyleri düştükçe yük algılarının arttığını ifade etmiştir. ${ }^{25}$ Bizim çalışmamızda ise bakım verenlerin eğitim düzeyleri karşılaştırılmasında fark bulunamamıştır (Tablo 2).

Çalışmamızın çeşitli kısıtlılıkları vardır. Birincisi verilerin sadece bir hastaneden toplanmış olması nedeniyle elde edilen sonuçlar tüm bakım verenleri temsil etmemektedir. Bakım verenlere eşlik edebilecek psikiyatrik değerlendirme ölçeğinin kullanılmamış olması bir diğer kısıtlılığımızdır. Ayrıca bakım veren yükünü etkileyen birçok sosyokültürel etken vardır. Bu konuda daha fazla katılımcının olduğu, farklı kültürlerden ve bölgelerden katılımcıları kapsayan çok merkezli araştırmalara ihtiyaç vardır. Çalışmamızın güçlü yönü ise literatürde OSB ve DS gibi bakım gerektiren hastalıkların bakım verme yüklerini karşılaştıran ilk çalışmalardan birisidir. Dolayısıyla araştırmamız bu yönüyle ileride yapılacak çalışmalara katkı sunabilir.

Sonuç olarak çalışmamızda OSB'ye bakım verenlerin bakım yüklerinin daha yüksek olduğunu, bakım verenlerin çoğunluğunun kadınlardan oluştuğu tespit edildi. OSB olan çocuklara bakım verenlerin yaşadıkları güçlükleri tanımlamak, bakım verme yüklerini belirlemek bu çocuklara bakım verenlere gerekli sosyal desteği sağlamak ve yaşam kalitelerini artırmak bu hastaların daha kaliteli hizmet alması ve hastalıklarının daha iyi yönetilmesi için gereklidir. 
Sakarya Tip Dergisi 2020;10(2):210-215

ÇOKYAMAN ve Ark., Otizm ve Zarit Bakııı Yük Ölçeği

\section{Kaynaklar}

1. Lord C. Elsabbagh M. Baird G. Veenstra-Vanderweele J. Autism Spectrum Disorder. Lancet 2018; 392:508-20

2. Schieve LA. Blumberg SJ. Rice C. Visser SN. Boyle C. The Relationship Between Autism And Parenting Stress. Pediatrics. 2007:114-21.

3. Hall HR. Graff JC. The Relationships Among Adaptive Behaviors Of Children With Autism, Family Support, Parenting Stress, And Coping. Issues Comprehensive Pediatric Nursing;2011;34:4-25.

4. Schieve L. Boulet S. Boyle C. Rasmussen S. Schendel D. Health OfChildren 3 To 17 Years Of Age With Down Syndrome In The 1997-2005 National Health Interview Survey. Pediatrics. 2009; 123: 253-60

5. Bull MJ. Committee on Genetics. Health supervision for children with Down syndrome. Pediatrics 2011; 128:393-06

6. Lim JW. Zebrack B. Caring For Family Members With Chronic Physical Illness: A Critical Review Of Caregiver Literature. Health Qual Life Outcomes 2004; 17(2):50

7. Bourke J. Ricciardo B. Bebbington A. Aiberti K. Jacoby P. Dyke P. Phisycal And Mental Health In Mothers OfChildren With Down Syndrome. J Pediatr 2008;153:320-26.

8. Siklos S. Kerns KA. Assesing Need For Docil Support In Parents Of Children With Autism And Down Syndrome. J Autism Dev Disord. 2006;36:921-33.

9. Zarit SH. Reever KE. Bach-Peterson J. Relatives Of The Impaired Elderly:Correlates Of Feelings Of Burden. Gerontologist.1980;20:649-55.

10. İnci FH. Erdem M. Bakım Verme Yükü Ölçeğininin Türkçe’ye Uyarlanmast Geçerlilik ve Güvenilirliği. Journal of Anatolia Nursing and Health Sciences.2008;11:85-95.

11. Tel H. Demirkol D. Kara S. Aydin D. Koah'l Hastaların Bakım Vericilerinde Bakım Yükü Ve Yașam Kalitesi. Turk Toraks Derg.2012;3:87-92.

12. Ergh T. Hanks R. Rapport L. Coleman R. Social Support Moderates Caregiver Life Satisfaction Following Traumatic Brain İnjury.J Clin Exp Neuropsychol. 2003;25:1090-01.

13. Van Den Heuvel E. De Witte L. Schure L. Sanderman R. Meyboom-De Jong B. Risk Factors For Burn-Out In Caregivers Of Stroke Patients, And Possibilities For İntervention. Clin Rehabil. 2001;6:669-77.
14. Türe E. Yazar A. Akın F. Aydin A. Evaluation Of Caregiving Burden İn Caregivers OfChildren With Chronic Illness. Bozok Tip Dergisi. 2018;3:46-53.

15. Centers For Disease Control And Prevention. Down Syndrome Prevalence At Birth-United States, 1983-1990. MMWR Morb Mortal Wkly Rep.1994; 43:617-22.

16. Etters L. Goodall D. Harrison B. Caregiver Burden Among Dementia Patient Caregivers: A Review Of The Literature. J Am Acad Nurse Pract. 2008;20:8:423-28.

17. Akșit S. Cimete G. Çocuğun Yoğun Bakım Ünitesine Kabulünde Annelere Uygulanan Hemșirelik Bakımının Annelerin Anksiyete Düzeyine Etkisi. C.Ü. Hemşirelik Yüksekokulu Dergisi. 2001;5:2:25-36

18. Alahan N. Aylaz R. Yetị̧ G. Kronik Hastalı̆̆ı Olan Çocuğa Sahip Ebeveynlerin Bakım Verme Yükü. İnönü Üniversitesi Sağlık Bilimleri Dergisi. 2015;4:2:1-5.

19. Mccubbin M. Family Stres, Resources, And Family Types: Chronic Illness In Children.Family Relations. 1988;37:203-10.

20. Babaoğlu E. Öz F. Terminal Dönem Kanser Hastasına Bakım Veren Eșlerin Duygusal Ve Sosyal Sorunları Arasındaki İlișki. Hemșirelikte Araștırma Gelistirme Dergisi.2003;2:24-33.

21. Karahan A. İslam S. Fiziksel Engelli Çocuk Ve Yaşl Hastalara Bakım Verme Yükü Üzerine Bir Karşılaştırma Çalıșması. Marmara Üniversitesi Sağlık Bilimleri Enstitüsü Dergisi. 2013;3:1-7.

22. Lecavalier L. Leone S. Wiltz LJ. The Impact Of Behaviour Problems On Caregiver Stres In Young People With Autism Spectrum Disorders.J Intellect Disabil Res.2006;50:172-83.

23. Estes A. Munson J. Dawson G. Koehler E. Zhou X. H. . Abbott R. Parenting Stress And Psychological Functioning Among Mothers Of Preschool Children With Autism And Developmental Delay. Autism.2009; 13:375-87.

24. Bromley J. Hare DJ. Davison K. Emerson E. Mothers Supporting Children With Autistic Spectrum Disorders: Social Support, Mental Health Status And Satisfaction With Services. Autism.2004; $8: 409-23$

25. Datta S. Russell P. Gopalakrishna S. Burden Among The Caregivers Of Children With Intellectual Disability: Associations And Risk Factors. Journal Of Learning Disabilities. 2002:6:4:337-50. 